\title{
Entre o convencer e o admirar: estratégias discursivas da Igreja Universal na Programação IURD e na campanha Eu Sou A Universal
}

\author{
Marco Túlio Sousa \& Jênifer Rosa de Oliveira \\ Universidade do Vale do Rio dos Sinos / Universidade Metodista de São Paulo \\ E-mail: marcotuliosousa@hotmail.com/ jeniferdeoliveira@gmail.com
}

\begin{abstract}
Resumo
O presente trabalho expõe uma análise comparativa de dois produtos midiáticos da Igreja Universal do Reino de Deus (IURD): uma peça publicitária da campanha "Eu sou a Universal"disponível na internet e um testemunho proferido por um fiel veiculado em um dos programas televisivos que compõem a Programação IURD (conjunto de programas que a igreja exibe durante a madrugada) do estado brasileiro de Minas Gerais. Em comum os objetos analisados trazem a história de Cláudio Soares, ex-

mendigo que se tornou empresário bem sucedido. Tendo como referenciais teóricos a Análise de Discurso franco-brasileira de Eni Orlandi e Michel Pêcheux, bem como elementos da retórica aristotélica, procuramos identificar as diferentes estratégias discursivas que a IURD utiliza a partir dos dois contextos enunciativos. Dessa forma, observamos em que tais estratégias diferem de acordo com os objetivos específicos de cada produto e o público para os quais eles se destinam.

Palavras-chave: Igreja Universal do Reino de Deus; análise de discurso; programação IURD, Eu Sou A Universal.

\section{Between convincing and admiring: The Universal Church's discursive strategies present in the UCKG programming and its campaign "I am Universal".}

\begin{abstract}
This paper introduces a comparative examination of two media products, which have been delivered by the Universal Church of the Kingdom of God (UCKG): An advertising piece for the "I am Universal"campaign, available on the internet and a believer's testimony, which has been publicized in one of the shows the UCKG programming is comprised of (set of shows exhibited by the church during the

early hours), broadcast in the Brazilian State of Minas Gerais. Both objects of study share the history of Cláudio Soares, this ex-homeless man who has become a well-succeeded entrepreneur. Making use of the Franco-Brazilian Discourse Analysis of Eni Orlandi and Michel Pêcheux as our theoretical referential, additionally to elements from the Aristotelian Rhetoric, we aimed at identifying the various dis-
\end{abstract}

Data de submissão: 16-01-2018. Data de aprovação: 09-03-2018 .

A Revista Estudos em Comunicação é financiada por Fundos FEDER através do Programa Operacional Factores de Competitividade - COMPETE e por Fundos Nacionais através da FCT - Fundação para a Ciência e a Tecnologia no âmbito do projeto Comunicação, Filosofia e Humanidades (LabCom.IFP) UID/CCI/00661/2013.
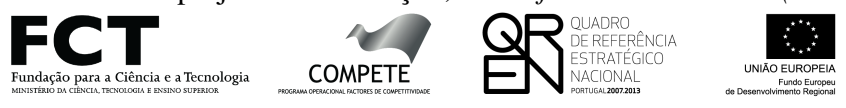

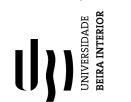


cursive strategies that the UCKG deploys, based on these two enunciating contexts. Given these points, it has been observed that such strategies differ, ac- cording to the specific objectives of each product and the audience for which they are intended.

Keywords: Universal Church of the Kingdom of God; discourse analysis; UCKG programming; I am Universal.

\section{Introdução}

TO DIA 10 de julho de 2012 a versão do programa televisivo Desafio da Cruz da Igreja Universal do Reino de Deus (IURD) no estado de Minas Gerais (Brasil) transmitia o testemunho de Cláudio Soares, ex-mendigo que havia se tornado empresário de sucesso. O conteúdo compunha a Programação IURD - conjunto de programas de propriedade da Igreja Universal transmitidos pela TV Record durante a madrugada - e chamou a atenção durante a pesquisa de um dos autores deste trabalho (Sousa, 2014) por trazer um testemunho mais longo do que os costumeiramente exibidos.

Posteriormente, em outro trabalho (Oliveira, Sousa, 2014) percebeu-se que o mesmo personagem aparecia na campanha publicitária "Eu Sou a Universal", promovida pela IURD desde o ano de 2013. O fato de uma mesma história ser utilizada em diferentes produtos midiáticos da igreja despertou o interesse em compreender de que forma ela foi apropriada pela instituição religiosa nos dois contextos. Assim, neste artigo, realizamos uma análise comparativa em que buscamos identificar diferenças entre as estratégias discursivas utilizadas em cada produção a fim de entender de que modo os testemunhos, que ocupam papel central nas igrejas pentecostais e neopentecostais, assumem novas configurações a partir de articulações com a mídia que se fazem a partir dos objetivos pontuais das denominações religiosas.

Tendo em vista ser uma análise discursiva, trataremos de alguns conceitos da Análise de Discurso que nos são úteis nesta investigação.

\section{Análise de Discurso e Estratégias Discursivas}

A Análise de Discurso (AD) francesa de filiação pecheutiana compreende que os sentidos que emergem nas enunciações se constroem a partir do atravessamento da materialidade linguística, do inconsciente humano e do contexto sócio-histórico. Os sentidos não são dados exclusivamente no texto, de forma imanente, mas também nas relações que se constroem para além dele, compreendendo tanto o âmbito histórico quanto o situacional. Assim, um novo sentido só será possível em referência aos conjuntos de enunciados já existentes (interdiscurso) e a depender da ação dos sujeitos no momento da formulação (intradiscurso). Logo, no contato com o empírico o analista deve levar em conta tanto o caráter histórico/ ideológico quanto as especificidades que permeiam enunciações particulares (ex: o meio de comunicação utilizado, os sujeitos envolvidos e suas possíveis intencionalidades).

Pensando nisso nos próximos itens procuramos em um primeiro momento problematizar a inscrição sócio-histórica da IURD na sociedade brasileira para em seguida apresentar brevemente os resultados das análises discursivas feitas em outros trabalhos (Oliveira, Sousa, 2014; Sousa, 
2014). A partir deste preâmbulo realizamos o estudo comparativo das duas situações de enunciação, observando semelhanças e diferenças nas estratégias discursivas adotadas e os sentidos que emergem, tendo em vista conceitos da AD que mobilizamos para pensar tais questões: Formação Discursiva e Projeções Imaginárias.

Formação Discursiva diz respeito a uma regionalização do interdiscurso, o qual nada mais é do que o conjunto de formulações feitas e já esquecidas que determinam o que dizemos (Orlandi, 2005: 33). Os sentidos são tomados pelos sujeitos de forma naturalizada, fazendo com que não reconheçam as filiações histórico-sociais que neles operam. Tal efeito de evidência corresponde ao trabalho da ideologia no plano discursivo. Todavia, de forma inconsciente ou não, nas operações discursivas que permeiam nosso cotidiano os atores sociais tensionam as formulações já dadas, abrindo margem tanto para reafirmações quanto para desvios/ inovações criativas, ainda que em referência à ideologia fundante.

Tomemos a proposição de Orlandi (2005: 43): “a Formação Discursiva se define como aquilo que numa formação ideológica dada - ou seja, a partir de uma posição dada em uma conjuntura sócio-histórica dada - determina o que pode e deve ser dito". Vemos, portanto, que ela funciona como um conjunto regras/ normas que informam sobre o lugar dos sujeitos e de suas formulações a partir dos contextos de enunciação. Dessa forma, quando os sujeitos e as materialidades significantes por eles partilhadas movem-se de uma formação discursiva para outra diferentes sentidos podem surgir. Uma mesma frase dita por um aluno ou por um professor em aula tem diferentes valores para aqueles que ali se encontram.

O conceito de Formação Discursiva nos chama a atenção para gestos de sentido que apontam para uma amarração do ideológico com o inconsciente. Porém, sabemos que intencionalidades permeiam nossas comunicações, este aspecto sobressai nos produtos midiáticos que investigamos. $\mathrm{Na}$ AD francesa Osakabe (1999) procura pensar aspectos persuasivos a partir de uma perspectiva discursiva.

Segundo ele, existe um mecanismo de "projeções imaginárias" que condiciona o dizer. O enunciador projeta um conjunto de possíveis reações de acordo com a "imagem" que ele pensa que o outro faz dele e daquilo que vai expressar. Além disso, as estratégias discursivas dependem de inúmeros fatores, tais como: quem é o ouvinte/ destinatário, a circunstância, o lugar e o conteúdo do que se pretende dizer. Levando em conta tais aspectos é que os materiais significantes são construídos para variados fins, dentre eles, persuadir alguém. Midiaticamente esta questão para nós analistas se complexifica porque o público de uma mensagem não pode ser imediatamente determinado pelos investigadores, podendo sua recepção ocorrer em diferentes temporalidades e situações. Não obstante, ao observar com cuidado as estratégias discursivas utilizadas e as filiações sócio-históricas dos enunciados podemos tentar inferir um possível destinatário e refletir com um pouco mais de sofisticação sobre os modos como uma instituição, tal como a IURD, projeta uma imagem de si na sociedade brasileira por meio dos testemunhos de seus fiéis. Para tanto, é importante trazer um breve histórico sobre a igreja. 


\section{Igreja Universal: breve contextualização}

A Igreja Universal do Reino de Deus foi fundada em 1977 no Rio de Janeiro por Edir Macedo, Romildo Ribeiro Soares e Roberto Lopes. Desde então apresentou rápido crescimento, vindo a se tornar a quarta maior igreja evangélica em número de fiéis no Brasil ${ }^{1}$. A IURD pertence ao segmento neopentecostal, cujas instituições têm como características em comum: 1) exacerbação da guerra espiritual contra o Diabo e seus seguidores; 2) descolamento dos usos e costumes de santidades adotados pelas demais igrejas pentecostais; 3) estrutura administrativa em moldes empresariais; 4) pregação enfática da Teologia da Prosperidade (Mariano, 1999: 36).

Esta última nos interessa para este trabalho, visto que se relaciona diretamente ao objeto em análise. "A Teologia da Prosperidade valoriza a fé em Deus como meio de obter saúde, riqueza, felicidade, sucesso e poder terrenos" (mariano, 1999: 158, grifos do autor). Assim, destoa do ascetismo típico das igrejas pentecostais que surgiram no Brasil nas décadas anteriores e que via na negação dos prazeres da carne e das coisas do mundo uma forma de se aproximar de Deus. Diferentemente, tal teologia "promete prosperidade material, poder terreno, redenção da pobreza nesta vida. Ademais, segundo ela, a pobreza significa falta de fé, algo que desqualifica qualquer petulante à salvação" (Mariano, 1999:159). É comum que nos cultos fiéis que passaram por dificuldades financeiras e posteriormente vivenciaram alguma mudança nessa área contem suas experiências na forma de testemunho. Nele, eles atribuem a transformação referida a Deus e à igreja.

Tais "demonstrações de prosperidade" se dão não apenas nos testemunhos apresentados nos cultos e na mídia, mas também na forma como a igreja constrói sua identidade historicamente. Em classificação proposta por Ari Pedro Oro (2007), uma das características apontadas como definidoras da instituição é a de "igreja da exacerbação" ${ }^{2}$. Ou seja, a instituição procura sempre demonstrar seus êxitos de maneira que chamem a atenção da sociedade. Isso é feito em diversas frentes, tais como: pela representatividade na política (há pastores ocupando cargos no alto escalão nos poderes legislativo e executivo); pela construção de templos em espaços amplos e suntuosos localizados em pontos estratégicos e de fácil acesso por transporte público (um dos exemplos mais recentes é o Templo de Salomão, inaugurado em São Paulo em julho de 2014, com capacidade para 10 mil pessoas sentadas e custo estimado em 670 milhões de reais); e pela presença em todas as mídias ${ }^{3}$.

1. As demais são: Assembleia de Deus, Batista e Congregação Cristã do Brasil. Embora esteja entre as mais numerosas do país vale lembrar que o Censo de 2010 do Instituto Brasileiro de Geografia e Estatística (IBGE) indicou que pela primeira vez a IURD perdeu adeptos. Isso se deu em um cenário de conflito com outras denominações evangélicas, como a Igreja Mundial do Poder de Deus de Valdemiro Santiago, ex-pastor da IURD. Voltaremos a este ponto em outro momento.

2. As outras são: "igreja religiofágica" e "igreja macumbeira". A primeira diz respeito ao fato da IURD construir seu repertório simbólico incorporando crenças e ritualidades de outras igrejas e religiões, mesmo as consideradas adversárias, como Igreja Católica, a Umbanda e o Kardecismo. Já a segunda enfatiza a apropriação de rituais e elementos simbólicos da Umbanda e do Camdomblé, tais como o uso de roupas brancas, galhos de arruda e vocabulário específico nos cultos. Para mais detalhes, conferir Oro (2007).

3. Embora Oro $(2005-2006$; 2007) não trate deste aspecto poderíamos considerar também as narrativas que a IURD faz sobre si mesma como exemplos do que ele denomina como "igreja da exacerbação". Na ocasião da comemoração dos 35 anos da instituição em 2012 a IURD trouxe em seus periódicos Folha Universal e Folha de Portugal, veiculados 
Neste último ponto chamam a atenção: o jornal impresso Folha Universal (tiragem semanal de 1,5 milhão de exemplares), o portal Universal.org (www.universal.org), a Line Records (maior gravadora no estilo de música gospel do Brasil) e mais de 70 emissoras de rádio (Modesto, 2012). No campo televisivo destaca-se a TV Record, que atualmente disputa a vice-liderança em audiência no Brasil. A emissora conta ampla abrangência em território nacional e tem canais em outros continentes onde além da programação comum aos canais de variedades leva conteúdo de caráter religioso, como a Programação IURD, na qual figura um dos testemunhos de Cláudio Soares, cuja análise apresentamos a seguir.

\section{Programação IURD}

A Programação IURD corresponde a um conjunto de programas de propriedade da Igreja Universal transmitidos pela TV Record durante a madrugada. As edições dos programas são regionais e eles são apresentados pelos pastores que atuam nos estados em que a Programação é veiculada. Em pesquisa realizada por um dos autores deste texto (Sousa, 2014) foi feita uma análise da edição da Programação IURD de Minas Gerais no mês de julho de 2012, na qual o testemunho de Cláudio Soares foi apresentado em duas ocasiões (10/07/2012 e 13/07/2012).

A Programação é exibida diariamente, com duração aproximada de 5 horas, sendo que aos sábados há acréscimo de uma hora e no domingo de duas. Na época da pesquisa compreendia sete programas, além daqueles que não possuíam nomenclatura específica. São eles: Nação dos Vencedores, Ponto de Luz, Fala Que Eu Te Escuto, Desafio da Cruz, Casos Impossíveis, Terapia do Amor e Plantão da Fé. Diversos pastores se revezam na apresentação, ficando a maioria deles fixa em programas específicos. Isso se explica pela relação direta que cada programa tem com os cultos promovidos pela IURD em sua sede estadual. É frequente o pastor-apresentador convidar as pessoas com quem conversa por telefone na TV a participarem da "reunião" que ele estará ministrando. Ex: o Nação dos Vencedores, que aborda problemas financeiros era apresentado pelo pastor Marcelo Moraes, responsável pelo culto de segunda, também focado no tema.

O formato dos programas é similar. O cenário é composto por um fundo de cores frias e uma tela que mostra o nome do programa ou imagens panorâmicas do templo sede da IURD em Belo Horizonte (ver imagens). O pastor apresentador, posicionado à frente da tela, fala sempre olhando para a câmera, dirigindo-se ao espectador. As exceções se dão quando há dois apresentadores ou convidados, o que é raro.

respectivamente no Brasil e em Portugal, reportagens sobre a sua história nas quais se exalta o sucesso da igreja por causa da sua expressiva presença na mídia e pelos templos espaçosos e confortáveis. (Carvalho, Sousa, 2014). 


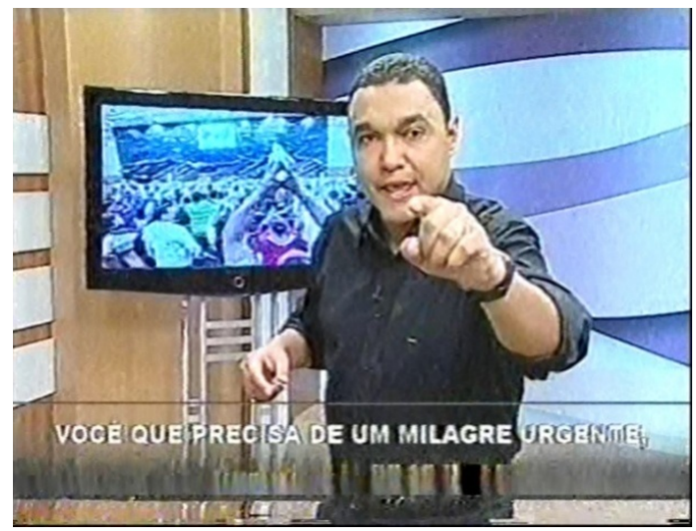

Figura 1. Terapia do Amor - 10/07/2012. Pastor Luciano Machado.

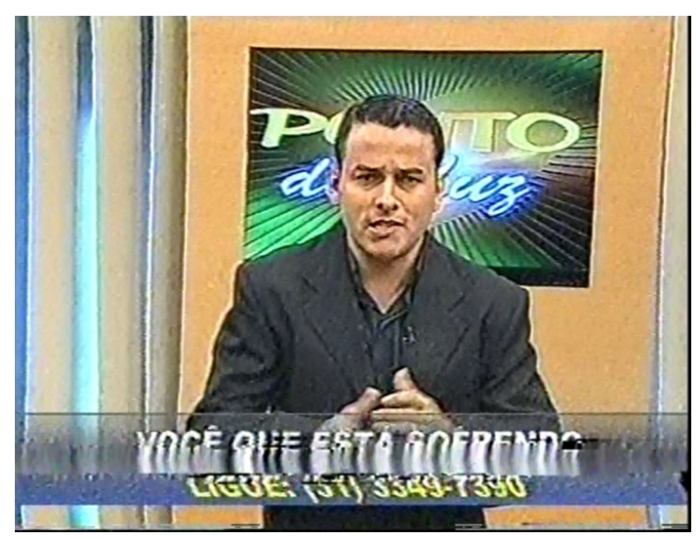

Figura 2. Ponto de Luz - 10/07/2012. Pastor Lopes

O conteúdo também é parecido, embora os temas variem e os quadros possam ser pontualmente distintos. Geralmente os programas têm início com a saudação dos apresentadores, seguida de exemplos de situações de sofrimento (Exs: a esposa que brigou com o marido, a mãe cujos filhos são usuários de drogas etc). Depois o pastor conversa por telefone com um espectador que narra seus sofrimentos e lhe pede ajuda. Em outras oportunidades ele chama um vídeo, que pode ser uma matéria jornalística da TV Record ou uma simulação encenada por atores da IURD. Ambas possuem desfecho negativo causado por um problema aparentemente sem solução.

O programa volta em seguida para o estúdio onde o apresentador faz um breve comentário sobre o caso e discursivamente amplia a sua abrangência, afirmando que quem vive situações semelhantes também poderia resolvê-las se realizassem alguma ação relacionada à vida espiritual. $\mathrm{Na}$ sequencia é apresentado o testemunho de um fiel que vivenciou problema similar ao abordado. Entretanto, o desfecho da história é distinto, desta feita, positivo, devido à participação em alguma reunião/ campanha da IURD. A maioria dos testemunhos é gravada no altar do templo 
sede em Belo Horizonte durante os cultos. Lá o pastor faz uma série de perguntas em formato de "entrevista" ao fiel, que conta os dramas e a transformação vivenciada.

Por fim, o apresentador procura construir uma ligação entre a situação narrada e os supostos problemas vividos pelos espectadores, dizendo que estes também podem ser sanados caso a pessoa tome a mesma atitude do personagem do testemunho: procurar a IURD. Esta constitui a "arquitetura narrativa" que compõe a Programação IURD nos seus variados programas.

Ela compreende: 1) um caso específico em que há "narrativa de fracasso" (participação por telefone, exemplos do pastor, matérias); 2) um comentário/promessa do pastor que amplia o caso específico, relaciona com os possíveis problemas do espectador e informa-lhe que eles têm solução; 3) um testemunho que corresponde a uma "narrativa de sucesso" na qual a mudança de vida é associada à igreja e que apresenta tanto o fracasso como o posterior sucesso; 4) por fim, um comentário em que novamente se ampliam os problemas expressos no testemunho e se conecta à vida do espectador para enfim convidá-lo a ir ao templo, condição necessária para cumprimento da promessa (Sousa, 2014: 124).

Por mais que os recursos televisivos utilizados sejam distintos (um testemunho dramatizado no lugar do testemunho no templo, a ligação em vez de cenas de filmes ou simulação encenada por atores) eles são encaixados nos programas segundo tal arquitetura narrativa. Assim, parece-se querer promover uma "identificação-projeção" por parte do público, a fim de fazer com que este vá a alguma das "reuniões" da igreja:

A identificação se daria pela narrativa de fracasso: ao refigurar tal narrativa em sua experiência de "leitura" o indivíduo aproxima os problemas narrados ("mundo do texto") dos seus ("mundo do leitor"), nesse processo ele é auxiliado pelos pastores, que por sua vez ampliam a abrangência dos depoimentos. A projeção ocorreria por meio das "narrativas de sucesso". A transição entre uma narrativa e outra é feita pela "promessa de solução" proposta pelo pastor ao espectador. Em seguida o espectador toma contato com um testemunho que traz um problema semelhante ao exposto pela "narrativa de fracasso", mas agora com um desfecho distinto. Quando o personagem (que também é o narrador) chega ao ápice de seu sofrimento há o contato com a Universal. A partir daí sua vida se transforma e ele consegue solucionar o problema. A "narrativa de sucesso" funciona como prova de que a promessa do pastor é verdadeira. Ao refigurar a narrativa, o espectador que anteriormente se identificara com o problema narrado pode ser levado agora a acreditar que sua vida também pode ser modificada (Sousa, 2014: 124).

O testemunho de Cláudio Soares se insere na "arquitetura narrativa" como uma "narrativa de sucesso" do programa Desafio da Cruz. Antes de abordá-lo diretamente acreditamos ser importante discorrer sobre a campanha publicitária "Eu Sou A Universal", na qual figura o outro material analisado.

\section{Eu Sou A Universal}

A campanha 'Eu Sou a Universal” foi lançada pela IURD em março de 2013, período em que a disputa entre a Igreja Mundial do Poder de Deus, liderada por Valdemiro Santiago, e a IURD 
se acirrava e esta última perdia muitos fiéis. Em 2012, o relatório do Censo de 2010 divulgado pelo IBGE revelou que a IURD perdeu 229 mil adeptos entre os anos de 2000 e 2010, passando de 2.102 milhões para 1.837 milhões. Em contrapartida, a Igreja Mundial registrou um total de 215 mil seguidores, aparecendo pela primeira vez na lista de igrejas do Censo em pouco mais de uma década de existência. Tendo em vista esse contexto levantamos a hipótese (Oliveira, Sousa, 2014) de que a campanha surge como tentativa de se valorizar a imagem institucional da igreja entre seus fiéis, a fim de conter a diminuição de seu quadro de membros, e reposicioná-la na sociedade brasileira.

Basicamente, a campanha é constituída por uma série de narrativas de sucesso, contadas em primeira pessoa por supostos membros da IURD, que aparecem em imagens que trazem um microrrelato (geralmente nome e profissão) encerrado com a frase "Eu sou a Universal". Essas peças foram utilizadas nos mais variados tipos de mídia e suporte, como revistas, jornais, outdoors e busdoors. Os relatos também foram produzidos em formatos para veiculação em rádio e TV.

Também foi lançado um site próprio para a campanha (www.eusouauniversal.com/), que até a redação deste artigo continuava a ser atualizado. Lá as narrativas introduzidas pelas imagens são mais exploradas, por meio de textos, fotos e vídeos, nos quais os personagens aparecem sempre bem vestidos e em ambientes bem decorados, que evidenciam sua boa condição financeira. O site ainda direciona para a loja online da IURD, Arca Center, onde é possível adquirir souvenir com o slogan da campanha, e também para uma página do site da IURD, com o endereço dos templos. Este é, aliás, o único elemento que liga a instituição religiosa diretamente à campanha, uma vez que é apenas nessa página externa que a Universal é identificada como uma igreja.

Além do site oficial e da conta no youtube onde os vídeos são hospedados, a campanha também possui um perfil no twitter (@EuSouaUniversal) e outro no facebook (www.facebook.com/Eusoua Universal). Nesses espaços, os vídeos e as imagens com os microrrelatos são divulgados, bem como o link do site para que as narrativas detalhadas sejam acessadas. Nas redes sociais, é comum encontrar seguidores que, além de compartilhar o conteúdo em suas redes, se apropriam das estruturas narrativas da campanha e tecem seus próprios comentários na forma dos microrrelatos divulgados, como se também fossem personagens da campanha. 


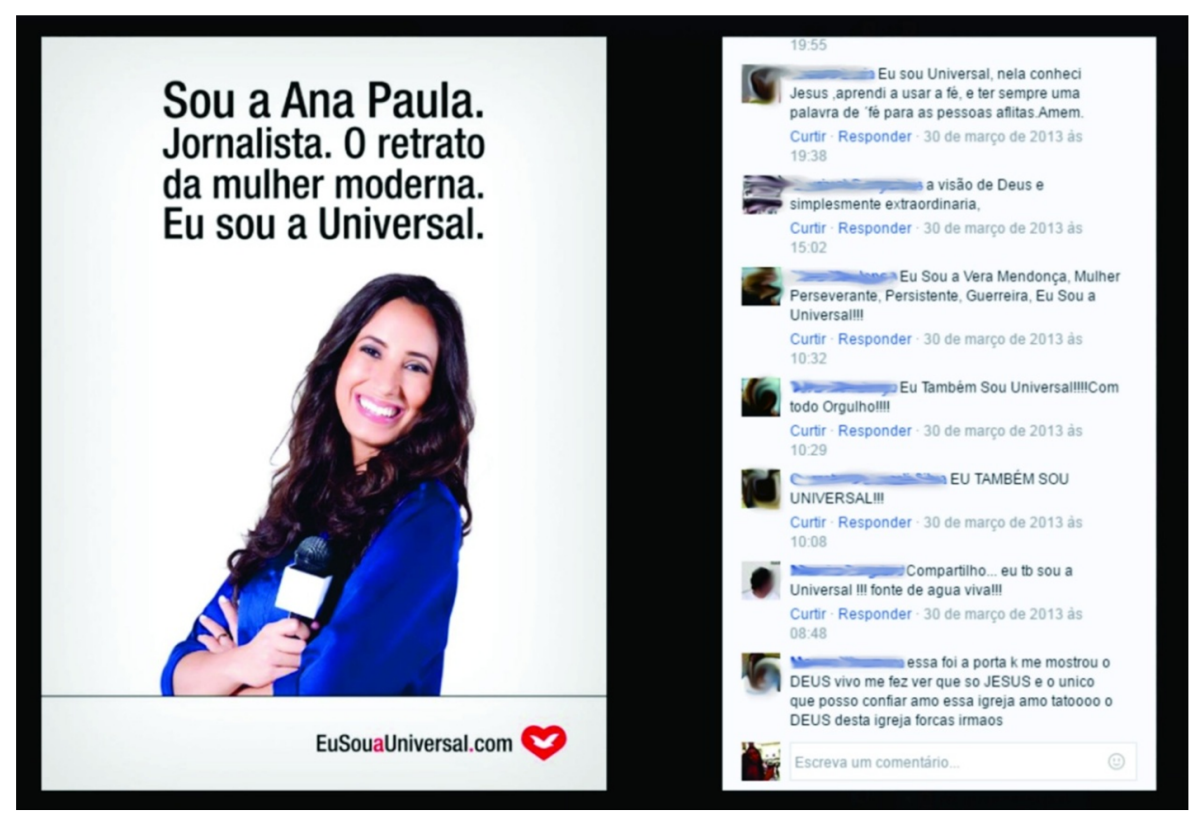

Figura 3. Imagem postada na página do Facebook da campanha no dia 28 de março de 2013, com alguns dos comentários de adesão.

Ao contrário dos cultos e dos programas de rádio e TV produzidos pela IURD, que enfatizam elementos místicos como exorcismos, orações em tom assertivo, objetos sagrados e a demonização das religiões afro e do catolicismo, o foco da campanha é a história de vida dos próprios personagens e suas atividades cotidianas. Após análise de algumas peças (Oliveira; Sousa, 2014), verificamos que o que legitima o discurso dos personagens da campanha é o que eles mostram de si: seu sucesso profissional e sua boa condição financeira, traduzidos textualmente e esteticamente nas peças produzidas para campanha. A IURD se cola às narrativas de sucesso de seus fiéis, que só se reconhecem pertencentes à Universal depois que estão bem-sucedidos. Percebe-se que o interesse da campanha, antes de trazer uma imagem positiva da igreja, é trazer uma imagem positiva de seus fiéis.

Embora nos relatos a Universal seja associada ao sucesso do personagem que narra sua história, em nenhum momento durante a campanha esta é apresentada como uma igreja, e nem o discurso religioso fica evidente nas peças. Este só é perceptível para aqueles que reconhecem a logomarca da IURD, que está presente nas imagens divulgadas juntamente com os microrrelatos.

Pensando nas noções de "formação discursiva" percebemos como o sentido do significante "Universal" na construção discursiva da campanha se transmuta de uma "igreja" para uma marca comercial. Por meio da memória discursiva, do "já dito" (interdiscurso) pela e sobre a IURD, apenas a citação de seu nome basta para que o público associe o termo "Universal" à denominação religiosa, mostrando que esta já está enraizada no cotidiano brasileiro. Já o conceito de "formação discursiva" nos permite entender como este significante, embora preserve 
o sentido de "igreja", no contexto da campanha ganha ares de marca comercial uma vez que se insere em uma "formação discursiva" distinta, migrando do religioso para o publicitário, mas sem perder a relação de contiguidade com o primeiro (Oliveira, Sousa, 2014: 237).

Respeitando esta lógica é que a história de Cláudio Soares é trazida para a campanha, como mostraremos em seguida a partir da análise comparativa proposta.

\section{A história do mendigo que virou empresário na campanha Eu Sou a Universal e na Pro- gramação IURD}

O personagem e a os fatos contados nas duas histórias são os mesmos: Cláudio Soares, exmorador de rua, abandonado pela família quando criança, hoje é empresário bem sucedido e vive um casamento feliz. Na campanha sua história é abordada pelos seguintes meios: banner na página da campanha, com foto e microrelato contendo os dizeres "Sou o Cláudio Soares, de morador de rua, tornei-me empresário de sucesso. Eu sou a Universal"; vídeo de 3 minutos que intercala tomadas de Cláudio falando sobre sua vida e atores encenando momentos de seu passado; e texto em primeira pessoa no qual a história novamente é contada acompanhada de uma galeria de fotos.

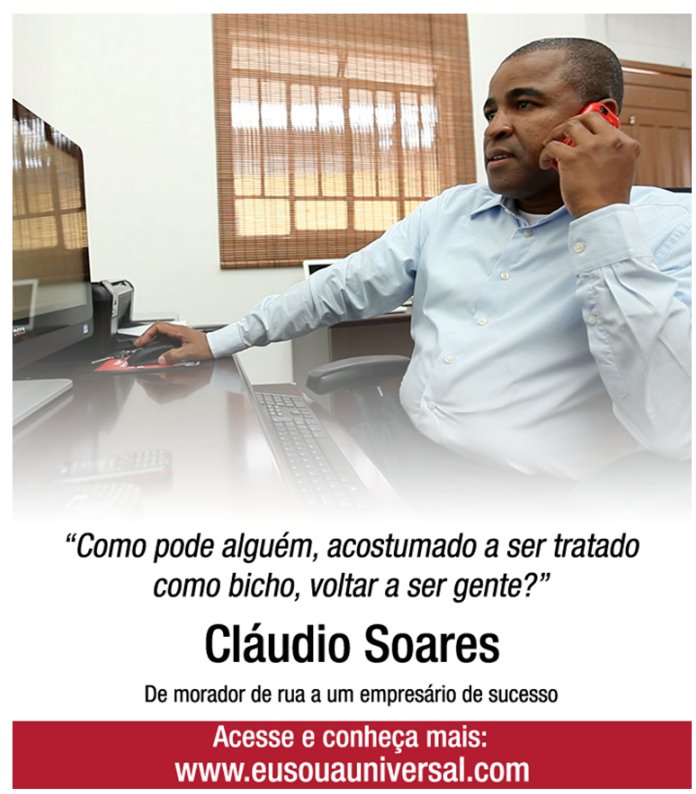

Figura 4. chamada para a história de Cláudio, postada no Facebook no dia 24 de junho de 2014.

O vídeo é dividido em dois momentos: um passado marcado pelo fracasso em contraste com a felicidade plena do presente. Importante notar que não é dito o que acontece na vida de Cláudio para explicar a passagem de uma condição para outra. Já no texto afirma-se que o marco do início da mudança é a participação em uma "reunião". No entanto, não se fala onde, quando, a natureza, nem o que teria ocorrido, apenas que a partir daquela ocasião ele saiu disposto a mudar. Os 
dois relatos (vídeo e texto escrito), tal como a imagem, terminam com o personagem reafirmando textualmente o slogan da campanha. O significante "Universal" é a única evidência que liga a história de vida à instituição. No entanto, isso é feito sem referência à religião

O mesmo não se percebe no vídeo do programa de TV. Nele Cláudio dá seu testemunho durante um dos cultos da IURD realizados na sede regional em Belo Horizonte. O vídeo é exibido durante o programa Desafio da Cruz, apresentado pelo pastor Everton Mendes, logo depois que este faz um convite para que os telespectadores com problemas espirituais compareçam a um culto. Assim, ele se articula a uma promessa feita pelo pastor de que aqueles que comparecerem à igreja e fizerem os sacrifícios terão suas vidas transformadas.

O vídeo apresentado no programa tem aproximadamente 10 minutos durante os quais Cláudio é entrevistado pelo pastor. O fiel traz um relato semelhante ao da campanha, mas dirige seu foco de acordo com o direcionamento dado pelo pastor a partir de algumas perguntas, as quais deixam evidente o discurso religioso. O significante "igreja" é mencionado 2 vezes e a palavra "Deus" é citada 16 vezes. Além disso, aparecem termos como "sacrifício", "obreiro" e expressões comuns ao repertório partilhado por membros da IURD, como "Deus vai me honrar", "aonde eu chego tem que chegar a luz" e "campanha de Israel". Tais marcas discursivas são inexistentes na participação do personagem na outra situação (campanha).

Diferentemente do vídeo da campanha, no qual o fator motivador da mudança de vida não é explicado, no Desafio da Cruz Cláudio narra detalhes de como se deu o processo e de como este está intrinsecamente relacionado a sua ida à IURD e ao seu engajamento nos rituais propostos. Assim, fala do dia em que chegou à igreja e de como o seu envolvimento com as práticas religiosas determinaram o sucesso alcançado em diferentes momentos e áreas da vida (casamento, fechamento de negócios etc). Terminado o vídeo, volta-se novamente para o estúdio, onde o pastor convida os telespectadores a participarem dos cultos que ele irá presidir, se utilizando da história de Cláudio para reafirmar o papel da igreja enquanto lugar que opera transformação de vida das pessoas por meio do poder divino.

\section{Considerações Finais}

Os dois produtos midiáticos analisados trazem uma mesma história produzida e divulgada pelas mídias da IURD. Entretanto, não podemos dizer que se trata da mesma narrativa. De acordo com Ricoeur (2010), pensar as narrativas implica considerar: 1) as condições a partir do qual ela foi tecida (mimesis I); 2) a ação dos sujeitos que a narram e elaboram (mimesis II), criativamente, uma história articulando uma série de fatos, fragmentos, em um todo passível de ser compreendido; 3) e, por fim, as próprias operações de leitura (mimesis III), que se fazem não de modo a reproduzir os sentidos propostos pelos narradores, mas de acordo com as referências próprias daquele que a interpreta, o que faz com que a interpretação seja, tal como a composição da narrativa, também criativa.

A tarefa daqueles que analisam textualidades é também um exercício interpretativo (Ricoeur, 1991, p. 158), mas que, diferentemente do senso comum, leva em conta o rigor científico, tem metodologia de análise, como, por exemplo, a hermenêutica ricoeuriana, ou a análise de discurso que fazemos uso no presente caso. Assim, a partir da análise dos materiais significantes observa- 
mos que embora a história, os personagens e o narrador (a IURD) sejam os mesmos temos duas narrativas distintas, uma vez que os recursos acionados para contá-las e as estratégias discursivas diferem, o que gera, portanto, processos de significação cujas pistas cabem a nós identificar.

No testemunho exibido durante a Programação IURD os elementos religiosos são não apenas enfatizados, mas constituem uma mediação determinante para a compreensão da narrativa. Durante fala de Cláudio a transição da condição anterior para a atual é atribuída à instituição religiosa e as intervenções divinas que por meio desta ocorrem. O discurso religioso é declarado. A narrativa transcorre em um templo religioso e é veiculada em um programa que se confessa religioso. Logo, o que legitima a presença de Cláudio no programa é a interferência da instituição religiosa na sua vida. Pela perspectiva trazida por essa narrativa o sucesso de Cláudio é atribuído à própria IURD. É quando se associa à instituição que ele obtém sucesso.

Já na campanha fica nítido um apagamento de significantes ligados ao mundo religioso. A Universal aparece como uma marca comercial ou traço identitário que define a condição atual do personagem, mas não como ator que teve alguma influência no curso dos acontecimentos narrados. Ou seja, a mudança de vida do personagem não aparece diretamente ligada à instituição. O sucesso de Cláudio, nessa outra narrativa, é atribuído a ele próprio, que, por ser "a Universal", transfere esse sucesso para a IURD, que tem sua imagem associada a dele.

Ao se inserir no contexto mercadológico que caracteriza uma campanha publicitária a IURD silencia aquilo que caracteriza seu lugar de inscrição na sociedade: o discurso religioso. Assim, passa a funcionar como marca. Isso só é possível porque o significante Universal migra de sua "formação discursiva" original para funcionar em outra, ganhando outros sentidos. Uma hipótese que levantamos e que o estudo episódico permite reafirmar é que as estratégias discursivas variam de acordo com os objetivos. Na Programação IURD: é a Universal que provê o sucesso do personagem, então o objetivo parece ser levar novos membros para a igreja; na campanha: o personagem é quem traz a marca do sucesso e a IURD se cola à imagem dele. Assim, inferimos que o objetivo pode ser o de fortalecer a imagem institucional entre os próprios fiéis - o que seria uma reação à perda de membros, conforme dito anteriormente - e transformar o modo como a instituição é vista na sociedade, mostrando seus fiéis como pessoas bem sucedidas. Isso contradiz a percepção do senso comum de que seus frequentadores são pessoas de baixa renda e pouco estudo (Mariano, 1999).

Os dois produtos demonstram a flexibilidade da IURD em trabalhar sua imagem midiaticamente. Nas duas peças é possível perceber uma reafirmação do discurso da teologia da prosperidade, adotada pela IURD em suas pregações, uma vez que ambas se estruturam sobre a história de sucesso de um personagem. No entanto, na campanha, Cláudio, ao falar sobre si, oferece uma imagem positiva da igreja, que inserida em uma formação discursiva diferente, passa a funcionar como marca. Mesmo assim, a IURD é identificada pelo público, pois já faz parte do interdiscurso, e a história de Cláudio a liga ao universo das pessoas de sucesso.

Diferentemente, na Programação IURD, a estratégia discursiva para narrar a história de Cláudio adota uma projeção imaginária que toma para si um interlocutor que esteja vivenciando uma situação de fracasso, que possa se identificar com os momentos difíceis vivido pelo personagem e que se inspire nele para enxergar sua adesão aos cultos da IURD como caminho para mudar de vida. Nesse caso, de forma inversa ao que acontece na campanha, é a IURD que provê de sucesso o 
personagem e as pessoas que a procuram. Assim, o significante "IURD" se transmuta ao se mover de uma formação discursiva para outra. Passando do religioso ao publicitário a IURD agrega a si características de uma marca, conforme uma campanha publicitária, ocultando o religioso. No processo de midiatização muda também o caráter do testemunho. Na Programação IURD ele parece perder o vínculo com a dimensão comunitária que historicamente o caracteriza. Na campanha "Eu Sou A Universal" se vai além e o que ocorre é a dessacralização do religioso.

Este breve exercício analítico, a despeito de suas limitações, sugere-nos uma inferência abrangente. A despeito das diferentes estratégias discursivo-midiáticas utilizadas, nota-se que o investimento desta instituição religiosa na mídia relaciona-se direta ou indiretamente com seu projeto expansionista materializando-se em produtos pelos quais se procura tanto aumentar o número de membros (Programação IURD), quanto conter a evasão dos mesmos (Eu Sou A Universal), ainda que, neste último caso, se tenha de abrir mão do discurso religioso.

\section{Referências Bibliográficas}

Carvalho, C. A. de \& Sousa, M. T. de (2014). Narrar, lembrar, esquecer: os 35 anos da Igreja Universal na Folha Universal e na Folha de Portugal. Estudos em Comunicação, (17), 143166.

Castro, J. \& Duarte, A. (2012, junho 29). Censo: Igreja Universal perde adeptos, e Poder de Deus ganha. O Globo. Disponível: https://goo.gl/LROSZM. Acesso: 31/07/2016.

Mariano, R. (1999). NeoPentecostais: sociologia do novo pentecostalismo no Brasil. São Paulo: Loyola.

Modesto, C. M. (2012). 34 anos de evangelismo eletrônico. Observatório da Imprensa. Disponível em: https://goo.gl/0kQ0ow. Acesso: 12/08/2016.

Oliveira, J. R. \&, Sousa, M. T. de (2014). O fiel como garoto propaganda: análise discursiva de uma campanha publicitária da Igreja Universal do Reino de Deus. Novos Olhares, (3), 2.

Osakabe, H. (1999). Argumentação e discurso político. São Paulo: Martins Fontes.

Orlandi, E. P. (2005). Análise de discurso: princípios e procedimentos. Campinas: Pontes.

Oro, A. P. (2007). Intolerância religiosa e reações afro no Rio Grande do Sul. In V. G. da Silva (org), Intolerância religiosa: impactos do neopentecostalismo no campo religioso afrobrasileiro. São Paulo: Edusp.

Ricoeur, P. (1991). Do texto a acção: ensaios de hermenêutica II. Porto: Res.

Ricoeur, P. (2010). Tempo e narrativa: a intriga e a narrativa histórica - Tomo I. São Paulo: Martins Fontes.

Sousa, M. T. de. (2014). As narrativas do reino: análise narrativa de programas televisivos da Igreja Universal nas madrugadas mineiras. Dissertação de Mestrado em Comunicação Social. Programa de pós-graduação em Comunicação Social da Universidade Federal de Minas Gerais (UFMG), Belo Horizonte, Brasil. 